\title{
MALDI-TOF MS Analysis of Urinary Nucleosides
}

\author{
Bernd Kammerer, Antje Frickenschmidt, and Christoph H. Gleiter \\ Institute of Pharmacology and Toxicology, Division of Clinical Pharmacology, University Hospital Tübingen, \\ Tübingen, Germany
}

Stefan Laufer

Institute of Pharmacy, University of Tübingen, Tübingen, Germany

\section{Hartmut Liebich}

Medical Clinic, University Hospital Tübingen, Tübingen, Germany

\begin{abstract}
As RNA turnover seems to be impaired in cancer patients, modified nucleosides have been evaluated as potential tumor markers. Modified nucleosides are mainly formed posttranscriptionally in tRNA, set free during RNA metabolism, and excreted in urine. Especially methylated nucleosides play an important role, as their levels are higher in urine from cancer patients. For structural elucidation of known and unknown nucleosides from urine samples of cancer patients, MALDI-TOF MS and MALDI-PSD were used for the first time. This technique generally ensures high sensitivity, mass resolution, and accuracy. In our analytical approach we prepurified nucleosides from urine by affinity chromatography and subsequently separated them by semipreparative high performance liquid chromatography. The different fractions were collected separately and analyzed by MALDI-TOF MS and PSD-MALDI using a mixture of six low molecular weight calibrants for internal or external calibration. The molecular totals formulas based on a mass accuracy of $10 \mathrm{ppm}$ and below were calculated and a systematic data base search was performed. The inherent problem of the MALDI-technique, the reduced sensitivity for low molecular weight substances caused by matrix suppression effects, was reduced by our technique. We identified several nucleosides in urine, which were previously identified via retention times and UV spectra of standards after HPLC analysis. Eight further nucleosides were observed. This work demonstrates for the first time the potential of MALDI-TOF and PSD-MALDI in combination with semipreparative HPLC for assignment of nucleosides in urine. The particularly high mass accuracy of this mass spectrometric method provides opportunities for identifying unknown compounds. (J Am Soc Mass Spectrom 2005, 16, 940-947) @ 2005 American Society for Mass Spectrometry
\end{abstract}

$\mathrm{M}$ ore than 50 different nucleosides have been identified in urine from healthy people as well as from patients suffering from different kinds of cancer; some have been shown to be elevated in urine of cancer patients [1,2]. They are degradation products of ribonucleic acid (RNA), particularly tRNA (transfer RNA), and show various modifications [1]. A number of nucleosides occurring in urine are shown in Figure 1. Transfer RNA contains a wide variety of modified nucleosides, which influence the translational efficiency and precision as well as the sensitivity to the reading context and the reading frame maintenance. Nucleosides in precursor tRNA (pre-tRNA) are modified by enzymes like tRNA-methyltransferases or -synthetases after the transcription. Their function and kind

Published online April 26, 2005

Address reprint requests to Dr. B. Kammerer, Department of Clinical Pharmacology, University of Tübingen, Otfried-Müller Strasse 45, D-72076 Tübinigen, Germany. E-mail: Bernd.Kammerer@uni-tuebingen.de of modification (methylation, desaminization, conversion of uridine to pseuduridine etc.) depend on their location in the tRNA chain [1,3]. After having performed their task, the tRNA molecules are cleaved to nucleosides. Unmodified nucleosides are recycled for biosynthesis of new RNA, while modified ones are not substrates to the salvage enzymes and thus are set free in the blood circulation and excreted with urine [1,3]. In the meantime, 79 different modified nucleosides have been isolated from tRNA and have been characterized, all of which are derivatives of the nucleosides adenosine, guanosine, uridine, and cytosine [4]. Dudley et al. identified a new nucleoside, 5'-deoxycytidine, in the urine of a patient with terminal head and neck cancer [5]. In urine of head and neck cancer patients in other stages of the disease, this nucleoside did not occur. There may be a relation between cancer stage and the appearance of 5'-deoxycytidine in urine.

In the case of breast cancer, no reliable tumor markers for diagnosis in an early stage are available to the 

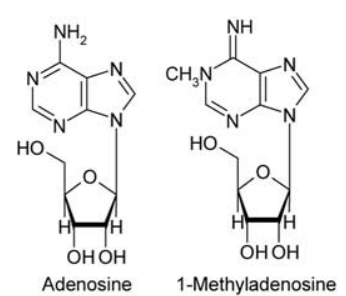<smiles>CCCCCCNC</smiles>
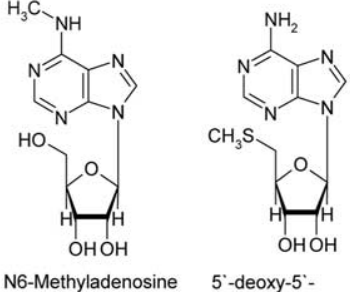

5'-deoxy-5 methylthioadenosine
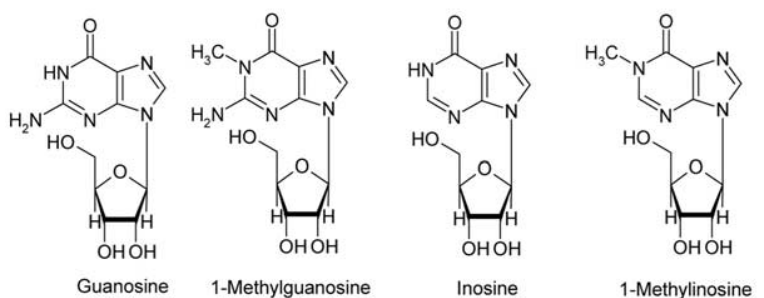

1-Methylinosine



1-Methylguanosine

Inosine
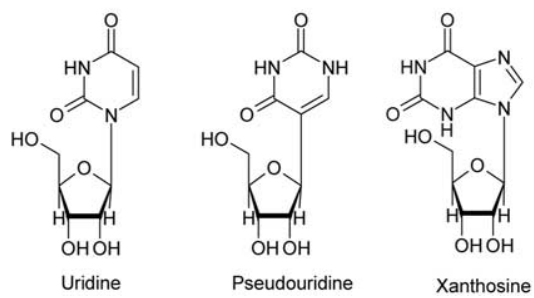

Figure 1. Structures of selected nucleosides occurring in urine.

present day [6]. About $11 \%$ of women in the European Union contract a malignant mamma carcinoma during their life. Only 5 to $10 \%$ are hereditary, while 90 to $95 \%$ occur spontaneously. The stages of mamma carcinoma are classified by the diameter of the primary tumor (T-classification), involvement of lymph nodes (N-classification), and the appearance of distant metastases (M-classification) [7].

Modified, especially methylated nucleosides have been shown to be elevated in urine from cancer patients because of an increased turnover of tRNA in tumor tissue [8]. Following this, the pattern of modified nucleosides may be used in tumor diagnosis [9]. It was shown that the levels of 1-methylinosine and N2,N2dimethylguanosine are higher in urine from breast cancer patients [10]. Increased levels of modified nucleosides were also observed in urine from patients suffering from leukemia [11], gastrointestinal cancer [12], or lung carcinoma [13].

Various methods have been applied for quantification of nucleosides in urine. Nucleosides were isolated from urine by solid phase extraction using phenylboronic acid gel. Uziel et al. prepared an affinity gel containing an immobilized phenylboronic acid group, which specifically binds cis-diols, as in nucleosides [14]. Gehrke and Kuo established an analytical method via high performance liquid chromatography (HPLC) [15], which was advanced over the years.

In our approach we used a modified method based on the work of Liebich et al. [16]. Modifications ${ }^{\circ}$ of the method were necessary as after the HPLC run, the fractions were examined further by mass spectrometry.

In the present work, we developed a method to examine unidentified nucleosides from urine including HPLC-separation, matrix-assisted laser desorption/ionization time-of-flight mass spectrometry (MALDI-TOF MS) and post source decay (PSD). With this method, we are particularly searching for new nucleoside markers, which are specifically elevated in urine from mamma carcinoma patients. Furthermore, the pattern of elevated nucleosides may be characteristic for the type or cancer stage.

\section{Experimental}

\section{Urine Samples}

To exemplify our method, the randomly collected urine of two patients with mamma carcinoma was examined. The samples were taken preoperatively. One patient was 80 years old and had an invasive ductal mamma carcinoma and a low-grade ductal carcinoma in situ (DCIS). The tumor was smaller than $2 \mathrm{~cm}$ and no involvement of the lymph nodes was diagnosed. The other patient was 70 years old and had an invasive lobar mamma carcinoma. The tumor was also smaller than $2 \mathrm{~cm}$. Metastases were diagnosed in the lymph nodes. This patient was undergoing chemotherapy prior to the operation. For comparison, two urine samples of healthy patients were also examined with HPLC.

\section{Sample Preparation}

Before performing the affinity chromatography, the $\mathrm{pH}$ of the urine samples was measured and, if necessary, alkalized by addition of ammonia to $\mathrm{pH} 8-9$.

The urine was extracted using $500 \mathrm{mg}$ of phenylboronic acid gel (Affigel 601, Bio-Rad, Munich, Germany). The gel was activated with $25 \mathrm{~mL}$ of $0.1 \mathrm{M}$ formic acid in methanol/water (1:1, vol:vol), washed with $25 \mathrm{~mL}$ of methanol/water (1:1) and equilibrated with $35 \mathrm{~mL}$ of $0.25 \mathrm{M}$ ammonium acetate, $\mathrm{pH}$ 8.5. Then, $10 \mathrm{~mL}$ of centrifuged urine containing $0.5 \mathrm{~mL}$ of a $0.25 \mathrm{mM}$ internal standard solution of isoguanosine was applied to the column. After washing with $20 \mathrm{~mL}$ of $0.25 \mathrm{M}$ ammonium acetate and twice with $3 \mathrm{~mL}$ of methanol/ water (1:1, vol:vol), the nucleosides were eluted with 25 $\mathrm{mL}$ of $0.1 \mathrm{M}$ formic acid. The solution was evaporated and dissolved in $0.5 \mathrm{~mL}$ of $25 \mathrm{mM}$ potassium dihydrogen phosphate, $\mathrm{pH} 5$.

\section{Reversed-Phase High-Performance Liquid Chromatography}

The liquid chromatography of extracted urine samples was performed on an Agilent (Waldbronn, Germany) $1100 \mathrm{HPLC}$ at $30^{\circ} \mathrm{C}$ with UV detection at 210 and 260 $\mathrm{nm}$. UV spectra (200-600 nm) were recorded over the whole running time. A $125 \times 2 \mathrm{~mm}, 4 \mu \mathrm{m}$ LiChroCART 
Supersphere ${ }^{\circledR} 100$ RP 18 column (Merck, Darmstadt, Germany) was used to separate the nucleosides. The chromatography was performed using a gradient of 5 $\mathrm{mM}$ ammoniumformiate buffer ( $\mathrm{pH}$ 5.0) (Solvent A) and methanol/water $(3: 2$, vol:vol) containing $0.1 \%$

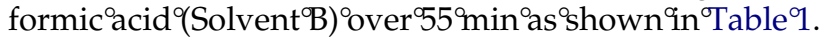
Methanol and formic acid were purchased from Merck.

\section{MALDI-TOF Analysis of Nucleosides}

The experiments were performed on a time-of-flight mass spectrometer, model Autoflex (Bruker, Bremen, Germany) with a 337-nm nitrogen laser. We used an AnchorChip Target with $0.4 \mu \mathrm{m}$ Anchors (Bruker). 2,5-dihydroxybenzoic acid (DHB) was obtained from Fluka (Taufkirchen, Germany). $\alpha$-cyano-4-hydroxycinnamic acid (CHCA) and the nucleosides adenosine (A), 1-methyladenosine $\left(\mathrm{m}^{1} \mathrm{~A}\right)$, N6-methyladenosine $\left(\mathrm{m}^{6} \mathrm{~A}\right)$, 5'-deoxy-5'-methylthioadenosine (MTA), cytidine (C), inosine (I), 1-methylinosine $\left(\mathrm{m}^{1} \mathrm{I}\right)$, guanosine $(\mathrm{G})$, 1-methylguanosine $\left(\mathrm{m}^{1} \mathrm{G}\right)$, N2-methylguanosine $\left(\mathrm{m}^{2} \mathrm{G}\right)$, uridine $(\mathrm{U})$, dihydrouridine (DHU), pseudouridine $(\Psi)$ 3-methyluridine $\left(\mathrm{m}^{3} \mathrm{U}\right)$, 5-methyluridine $\left(\mathrm{m}^{5} \mathrm{U}\right)$, and xanthosine $(\mathrm{X})$ were purchased from Sigma-Aldrich (Munich, Germany).

\section{Preparation of Matrix}

DHB was dissolved in TA solution $(0.1 \%$ trifluoracetic acid/acetonitrile, 2:1, vol:vol) to a concentration of 5 $\mathrm{mg} / \mathrm{mL}$ and sonicated for $5 \mathrm{~min} .0 .5 \mu \mathrm{L}$ of this freshly prepared solution was placed upon the MALDI-Target. For measurements with high mass accuracy, a thin layer of CHCA (saturated in acetone/ethanol, 1:1, vol:vol) was used.

\section{Sample Preparation}

For the analysis of standard nucleosides, $1 \mathrm{mg} / \mathrm{mL}$ solutions in $0.1 \%$ trifluoracetic acid were prepared. $1 \mu \mathrm{L}$ of these solutions was placed onto $0.5 \mu \mathrm{L}$ of DHBsolution on target. For determination with high mass accuracy, a thin layer of CHCA was prepared on the Anchor Chip target and the analyte solution added afterwards.

\section{Semipreparative HPLC and MALDI-TOF MS}

To analyze the isolated nucleosides in urine samples from breast cancer patients, different fractions from semipreparative HPLC separation were collected in 1.5 $\mathrm{mL}$ Eppendorf tubes, lyophilized, and solved again in $10 \mu \mathrm{L}$ of $0.1 \%$ TFA. The matrix solution for the MALDITOF MS analysis was placed onto the Anchor Chip target and $1 \mu \mathrm{L}$ of the sample solution was added. After having recorded the spectra of the different HPLC fractions, masses between 240 and 450 Da were examined by Post Source Decay (PSD) to determine the fragmentation and obtain indications of nucleosides.
Table 1. Solvent gradient of the HPLC separation

\begin{tabular}{ccc}
\hline Time (min) & $\begin{array}{c}\text { Ammoniumformate } \\
\text { buffer 5 mM, } \\
\text { pH 5 [\%] }\end{array}$ & $\begin{array}{c}\mathrm{MeOH} / \mathrm{H}_{2} \mathrm{O} \text { bidest } \\
(3 / 2, \text { vol/vol), } \\
0.1 \% \text { FA [\%] }\end{array}$ \\
\hline \hline 0 & 100 & 0 \\
30 & 85 & 15 \\
40 & 40 & 60 \\
50 & 100 & 0 \\
55 & 100 & 0 \\
\hline
\end{tabular}

\section{Calibration}

For calibration a standard mixture of caffeine $\left(\left[\mathrm{C}_{8} \mathrm{H}_{11} \mathrm{~N}_{4} \mathrm{O}_{2}\right]^{+}\right.$, monoisotopic molecular mass 195.099220), bamipine $\left(\left[\mathrm{C}_{19} \mathrm{H}_{25} \mathrm{~N}_{2}\right]^{+}\right.$, monoisotopic molecular mass 281.201779), etophylline $\left(\left[\mathrm{C}_{9} \mathrm{H}_{13} \mathrm{~N}_{4} \mathrm{O}_{3}\right]^{+}\right.$, monoisotopic molecular mass 225.098790), phenylbutazone $\left(\left[\mathrm{C}_{19} \mathrm{H}_{21} \mathrm{~N}_{2} \mathrm{O}_{2}\right]^{+}\right.$, monoisotopic molecular mass 309.160320), pyrimethamine $\left(\left[\mathrm{C}_{12} \mathrm{H}_{14} \mathrm{ClN}_{4}\right]^{+}\right.$, monoisotopic molecular mass 249.090699$)$ and piritramid $\left(\left[\mathrm{C}_{27} \mathrm{H}_{35} \mathrm{~N}_{4} \mathrm{O}\right]^{+}\right.$, monoisotopic molecular mass 431.281070) was used. An external calibration was performed before generating overview spectra. To generate spectra with high mass accuracy, an internal calibration was performed.

\section{Results and Discussion}

Although MALDI-TOF MS is used predominantly for determination of large molecules like polymers, proteins, and peptides, there have been successful applications $^{\circ}$ for $^{\circ}$ different $^{\circ}$ classes $^{\circ}$ of $^{\circ}$ small $^{\circ}$ molecules $^{\circ}$ [17]. Lidgard et al. used DHB and CHCA matrix for determination of nucleosides and other small molecules by MALDI-TOF ${ }^{\circ} \mathrm{MS}^{\circ}[18] .{ }^{\circ} \mathrm{In}^{\circ}$ our ${ }^{\circ}$ experiments, ${ }^{\circ} \mathrm{DHB}^{\circ}$ was discovered to be the most suitable matrix for analyzing nucleosides by MALDI-TOF MS with high sensitivity. However, we observed reduction of several nucleosides, especially adenosine and its metabolites, as shown $^{\circ}$ in $^{\circ}$ Figure $^{\circ} 2 .^{\circ}$ Similar $^{\circ}$ effects $^{\circ}$ were $^{\circ}$ observed $^{\circ}$ in previous ${ }^{\circ}$ examinations ${ }^{\circ} y^{\circ}{ }^{\circ}$ Koomen $^{\circ}{ }^{\circ} d^{\circ}{ }^{\circ}$ ussell $[19]$. ${ }^{\circ}$ To avoid this, CHCA would be the preferable matrix, but with less sensitivity.

As DHB is a matrix which usually forms large crystals, the resulting mass accuracy is not optimal. We determined a mass accuracy below $100 \mathrm{ppm}$ for external and below $40 \mathrm{ppm}$ for internal calibration. With a thin layer of CHCA matrix, a mass accuracy below 10 ppm was achieved when using internal calibration.

Using DHB matrix, 18 nucleosides were determined by MALDI-TOF MS. The limits of detection (LOD) vary from $100 \mathrm{fmol}$ to $10 \mathrm{pmol}$ (S/N 300). The nucleosides of lower basicity, especially the ones with pyrimidine base, show a higher LOD than purines, as shown in Table $^{\circ} 2 .^{\circ}{ }^{\circ}$ The ${ }^{\circ}$ resolution ${ }^{\circ}$ usually ${ }^{\circ}$ varies $^{\circ}$ in ${ }^{\circ} a^{\circ}$ range $^{\circ}$ from 5000 to 9000 . Dudley et al. determined LOD between 19 and 110 pmol for nucleoside standard solutions measured ${ }^{\circ}$ by $^{\circ}$ LC-ESI ${ }^{\circ} \mathrm{MS}^{\circ}[20]^{\circ}{ }^{\circ} \mathrm{Compared}^{\circ}$ with $^{\circ}$ these ${ }^{\circ}$ results, MALDI-TOF MS is the most suitable mass spectromet- 


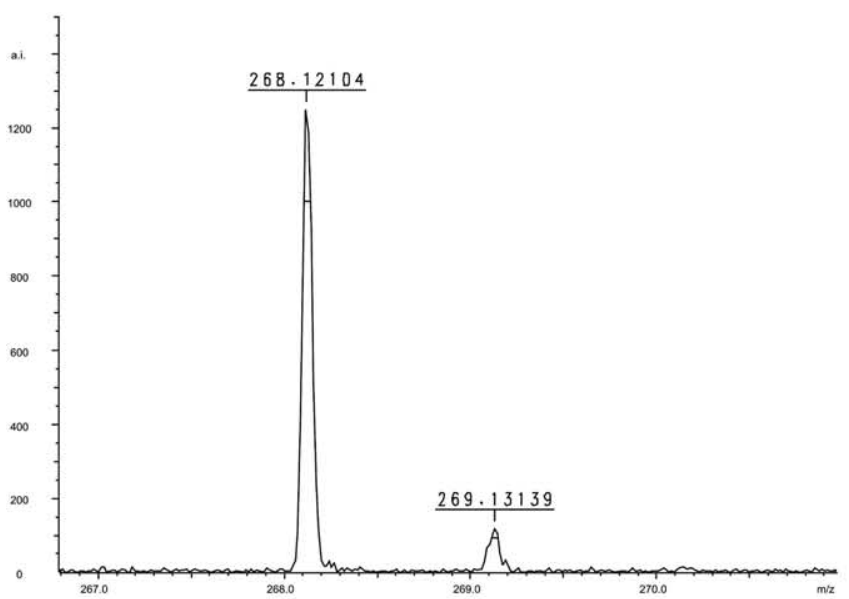

a)

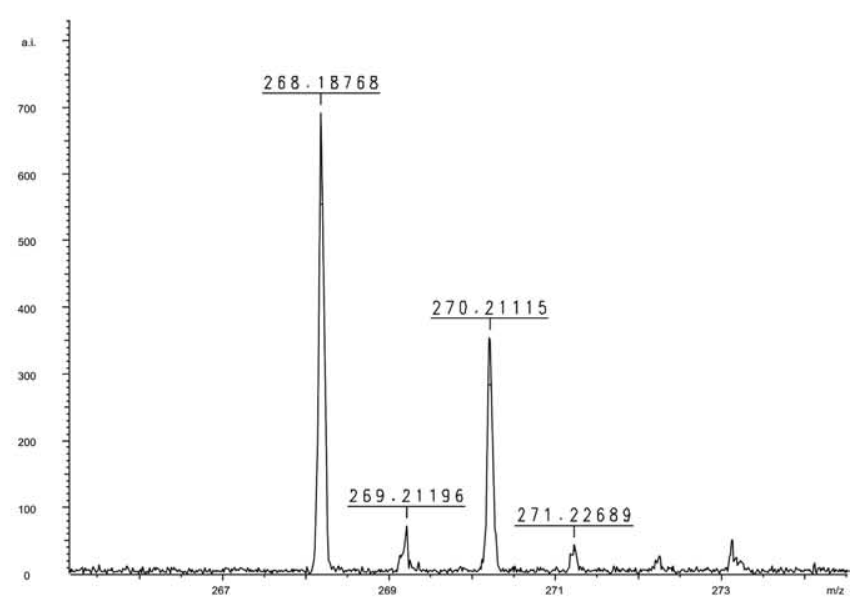

b)

Figure 2. MALDI-TOF spectra in reflecting mode of adenosine. Isotope distribution with CHCA (a) and DHB (b) matrix.

ric method to achieve high sensitivity, resolution, and mass accuracy. Dudley et al. also showed characteristic fragmentation ${ }^{\circ}$ ions ${ }^{\circ}$ of $^{\circ}$ nucleosides ${ }^{\circ}$ with $^{\circ}$ LC-ESI MS $/ \mathrm{MS}$ [20]. ${ }^{\circ} \mathrm{ESI}^{\circ} \mathrm{MS}^{\circ}$ and ${ }^{\circ} \mathrm{MALDI}-\mathrm{TOF}^{\circ} \mathrm{MS}^{\circ}{ }^{\circ}$ oth $^{\circ}{ }^{\circ}{ }^{\circ}{ }^{\circ}$ soft $^{\circ}$ ionization techniques. With MALDI-TOF MS the mass accuracy and resolution are usually better, while ESI MS can be coupled with liquid chromatography. The MS/MS spectra of MALDI-TOF MS and ESI MS are similar, but not identical. The major peak in the studies of Dudley et al. ${ }^{\circ}$ was ${ }^{\circ}$ that ${ }^{\circ}$ of $^{\circ}$ the ${ }^{\circ}$ protonated ${ }^{\circ}$ nucleic ${ }^{\circ}$ base $[20] .{ }^{\circ}$ Analogous fragmentation was seen in our PSD spectra.

The nucleosides decay under loss of $132 \mathrm{Da}$ (ribose), except pseudouridine, because of the stronger carbon-carbon bond between sugar and nucleic base. Dudley et al. observed the fragments $m / z 209,179$, and $155^{\circ}$ for $^{\circ}$ pseudouridine $^{\circ}\left[20{ }^{\circ} .^{\circ} \operatorname{In}^{\circ}\right.$ our $^{\circ}$ PSD-spectrum $^{\circ}$ of pseudouridine, $^{\circ}$ which $^{\circ}$ is $^{\circ}$ shown $^{\circ}$ in $^{\circ}$ Figure $^{\circ} 3,^{\circ}$ these masses also occurred. The PSD spectra of the other standard nucleosides show a characteristic decay between nucleic base and sugar. The protonated base is usually the major fragment. Other fragments of different intensity also occurred. They could not be assigned to structural fragments of the corresponding nucleosides yet, but the ones with high intensity still are characteristic indications for those nucleosides. Isomeric nucleosides (like $\mathrm{G} /$ isoG, $\mathrm{m}^{1} \mathrm{G} / \mathrm{m}^{2} \mathrm{G}, \mathrm{m}^{1} \mathrm{~A} / \mathrm{m}^{6} \mathrm{~A}$, and $\mathrm{m}^{3} \mathrm{U} / \mathrm{m}^{5} \mathrm{U}$ ) show identical characteristic PSD ions. They need to be identified by comparison with retention times and UV spectra of the standard substances after HPLC separation.

Uridine, DHU, 3-methyluridine and 5-methyluridine produce the same fragment of $m / z 133$. DHU produces the fragments $m / z 115, m / z 157$ and $m / z 181$. Uridine shows corresponding fragments with a difference of $2 \mathrm{Da}(\mathrm{m} / \mathrm{z}$ $113, m / z 155$ and $m / z$ 179). This speaks well for fragments, which still include the intact pyrimidine base. $m / z 155$ and $\mathrm{m} / \mathrm{z} 179$ occur in the PSD-spectrum of uridine as well as of pseudouridine. These fragments can be explained by fragmentation at S1 and loss of water, as formerly de- scribed $^{\circ}$ by $^{\circ}$ Dudley $^{\circ}$ et $^{\circ}$ al. $^{\circ}$ and $^{\circ}$ shown $^{\circ}$ in ${ }^{\circ}$ Figure $^{\circ} 3 .^{\circ}$ The fragmentation at S1 was first observed by Crow et al. in examinations ${ }^{\circ}$ of $^{\circ}$ nucleosides ${ }^{\circ}$ by $^{\circ}$ fast $^{\circ}$ atom $^{\circ}$ bombardment $(\mathrm{FAB})^{\circ}[21] . .^{\circ}$ The $^{\circ}$ pyrimidine ${ }^{\circ}$ nucleosides, ${ }^{\circ}$ except $^{\circ}$ cytidine, $^{\circ}$ show a S1-cleavage such as observed by Crow et al. for some nucleosides. With chemical ionization mass spectrometry, Wilson and McCloskey had also shown that nucleosides ${ }^{\circ}$ are $^{\circ}$ cleaved $^{\circ}$ in $^{\circ}$ this $^{\circ}$ way $^{\circ}[22]$.

The PSD spectra of adenosine and its metabolites $\mathrm{m}^{1} \mathrm{~A}, \mathrm{~m}^{6} \mathrm{~A}$, and MTA all contain a fragment of $\mathrm{m} / \mathrm{z} 136$. The nucleic base fragments of the methylated adenosines are fragmented further under loss of the methyl group, generating the adenine base $(m / z 136)$ such as adenosine and MTA. The methylated adenosines furthermore show a fragment which is caused by an S1 cleavage. The characteristic fragmentation ions of the analyzed nucleosides and a comparison with fragmentation ${ }^{\circ}$ with ${ }^{\circ} \mathrm{FAB}^{\circ}$ and ${ }^{\circ} \mathrm{CI}^{\circ}$ are $^{\circ}$ given $^{\circ}$ in $^{\circ} \mathrm{Table}^{\circ} 3$.

Prior to the MALDI-TOF examination, the semipreparative HPLC analysis is used to isolate the unidentified compounds from urine. Ten nucleosides were identified in the urine samples by retention times and UV spectra of the individual peaks in the HPLCchromatogram $^{\circ}\left(\right.$ Figure $\left.^{\circ} 4\right) .^{\circ}$ This $^{\circ}$ assignment $^{\circ}$ was $^{\circ}$ confirmed by the MALDI and MALDI- PSD results.

Table 2. Limits of detection of standard nucleosides

\begin{tabular}{lc}
\hline Nucleoside & Limit of detection \\
\hline \hline Adenosine & $100 \mathrm{fmol}$ \\
1-Methyladenosine & $100 \mathrm{fmol}$ \\
N6-Methyladenosine & $100 \mathrm{fmol}$ \\
MTA & $100 \mathrm{fmol}$ \\
Cytidine & $<2 \mathrm{pmol}$ \\
Guanosine & $<2 \mathrm{pmol}$ \\
Inosine & $<10 \mathrm{pmol}$ \\
Uridine & $<4 \mathrm{pmol}$ \\
Pseudouridine & $<10 \mathrm{pmol}$ \\
Xanthosine & $<2 \mathrm{pmol}$ \\
\hline
\end{tabular}




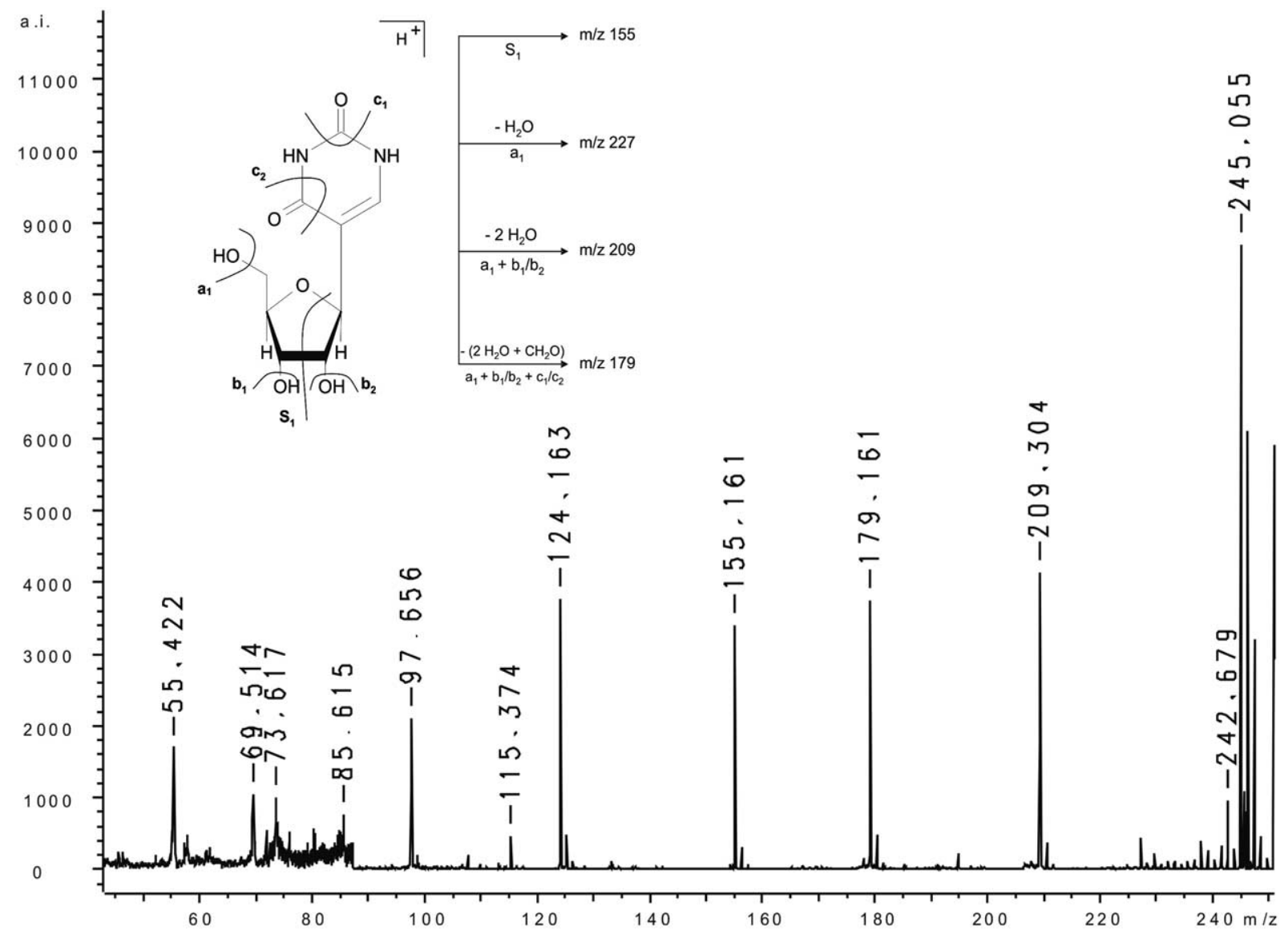

Figure 3. Post source decay spectrum and fragmentation of pseudouridine.

A number of the nucleosides contained in the standard solution were not found in our urine samples. Uridine, 3-methyluridine, 5-methyluridine, N6-methyladenosine, and guanosine do not seem to be present in significant amounts, as neither the HPLC-run nor the determination by MALDITOF offer clues to their presence. In the analytical work of $\mathrm{Xu}$ et al., these nucleosides were also minor components in urine samples of cancer patients ${ }^{\circ}[23]$.

Table 3. Comparison of fragmentation ions of nucleosides generated by PSD-MALDI, FAB and CI

\begin{tabular}{|c|c|c|c|}
\hline Nucleoside & $\begin{array}{l}\text { Characteristic fragmentions } \\
(\mathrm{m} / \mathrm{z}) \text { in PSD spectra }\end{array}$ & FAB [18] & $\mathrm{Cl}[19]$ \\
\hline Adenosine & $136,166,181$ & $268,250,237,178,164,136$ & $268,136,164,178,135,150,176$ \\
\hline 1-Methyladenosine & $136,150,180,192$ & n.i. & $268,136,164,150,178,192$ \\
\hline N6-Methyladenosine & $136,150,180,192$ & n.i. & $282,150,178,192,136$ \\
\hline MTA & 136,163 & n.i. & n.i. \\
\hline Cytidine & $112,137,228$ & $244,154,140,133$ & $244,112,140,154$ \\
\hline Inosine & 137,261 & n.i. & n.i. \\
\hline 1-Methylinosine & 136, 151, 201, 271 & n.i. & n.i. \\
\hline Guanosine & $136,152,271,194$ & $266,253,194,180,152$ & n.i. \\
\hline Isoguanosine & $136,152,271$ & n.i. & n.i. \\
\hline 1-Methylguanosine & 166, 136, 211 & $298,267,208,194,166$ & n.i. \\
\hline 2-Methylguanosine & $166,136,211$ & $298,208,180,166$ & n.i. \\
\hline DHU & $115,133,157,181,229$ & $247,229,157,143,115,133$ & n.i. \\
\hline Uridine & $113,133,155,179,231$ & $245,227,155,141,113,133$ & $245,113,141,155$ \\
\hline 3-Methyluridine & $127,133,169$ & $259,241,169,155,127,133$ & n.i. \\
\hline 5-Methyluridine & $127,133,169$ & n.i. & n.i. \\
\hline Pseudouridine & $155,179,209,113$ & 245, 227, 214, 155, 137, 133, 209 & $245,113,141,155,179,209$ \\
\hline Xanthosine & $136,153,200,271$ & n.i. & n.i. \\
\hline
\end{tabular}

Bold: nucleic base fragment, n.i.: not investigated 


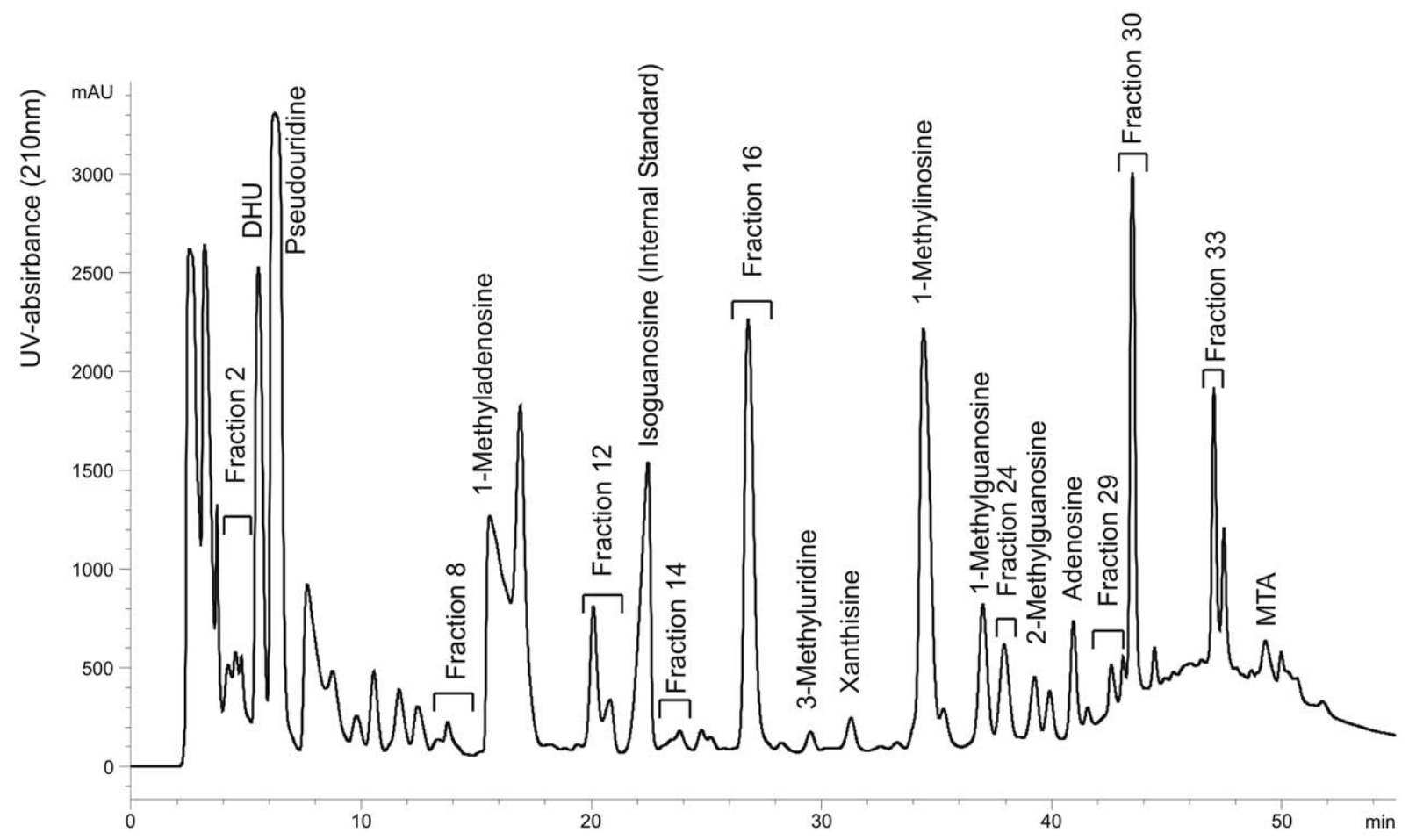

Figure 4. High performance liquid chromatography chromatogram of a urine sample from a breast cancer patient.

\section{General Procedure for Structure Proposal by Database Search}

A high mass accuracy is necessary for calculation of totals formulas with given elemental composition. For this calculation, Molecular Weight Calculator 6.22 (Matthew ${ }^{\circ}$ Monroe, $^{\circ}$ http://www.alchemistmatt.com ${ }^{\circ}$ was used. Nucleosides contain a minimum of nine carbon atoms, three oxygen atoms, and two nitrogen atoms. With a mass accuracy of $10 \mathrm{ppm}$ and looking for compounds fulfilling these restrictions, it is possible to narrow the number of totals formulas down to a few. The suggested totals formulas are then used to search for nucleoside structures systematically. For this search, SciFinder 2003 was used.

As a proof of concept experiment, a xanthosine standard was measured with the monoisotopic mass 285.0818 (based on a mass accuracy of $10 \mathrm{ppm}$ using internal calibration). For this mass and mass accuracy, Molecular Weight Calculator calculated 24 different totals formulas. Only one of the formulas fulfilled the conditions for elemental composition of nucleosides as described above. The search by SciFinder resulted in 132 hits, which were narrowed down to 40 compounds containing ribose. One of these compounds was xanthosine. In connection with the characteristic PSD spectrum, xanthosine could be identified. This example shows that with an accurate mass in connection with the fragmentation it is possible to obtain hints on the structure of unknown compounds.

In the HPLC fractions 12 and 16, new compounds with $\mathrm{m} / \mathrm{z} 271$ and the fragment ion $\mathrm{m} / \mathrm{z} 139$ occurred. Both fractions were analyzed with the described method. In fraction 16, $\mathrm{m} / \mathrm{z} 271.0918$ was measured and 16 different totals formulas were proposed. After narrowing the results by the restrictions mentioned above, two possible formulas remained. One of them led to no hits when searching by SciFinder. The other one resulted in 323 hits, which were narrowed to 33 compounds containing ribose. Two of these compounds are 1-ribosylpyridin-4-one-3-carboxamide and 1-ribosylpyridin-2-one-5-carboxamide (structures shown in Figure $\left.^{\circ} 5\right) .^{\circ}$ The $^{\circ}$ other $^{\circ}$ suggested ${ }^{\circ}$ structure $^{\circ}$ were $^{\circ}$ not naturally occurring compounds. Dutta et al. isolated $1-\beta$-D-ribofuranosylpyridin-4-one-3-carboxamide from human ${ }^{\circ}$ urine $^{\circ}$ in $^{\circ} 1979^{\circ}$ [24]. ${ }^{\circ}$ 1-Ribosylpyridin-4-one-3-

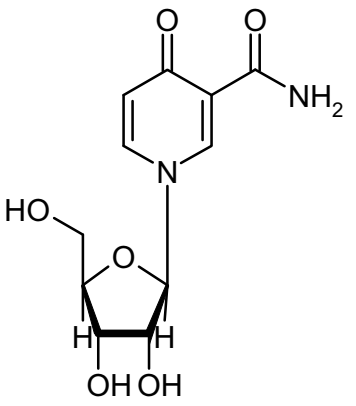

(a)<smiles>NC(=O)c1ccc(=O)n(C2OC(CO)(CO)C(O)C2O)c1</smiles>

(b)
Figure 5. Structures of 1-ribosylpyridin-4-one-3-carboxamide (a) and 1-ribosylpyridin-2-one-5-carboxamide (b). 
Table 4. MALDI-TOF MS and PSD MALDI results

\begin{tabular}{|c|c|c|c|c|}
\hline $\begin{array}{l}\mathrm{HPLC} \\
\text { fraction }\end{array}$ & $\begin{array}{c}\mathrm{RT} \\
\text { [min:sec] }\end{array}$ & $\begin{array}{c}\mathrm{m} / \mathrm{z}[\mathrm{Da}] \\
\text { (mass accuracy [ppm]) }\end{array}$ & $\begin{array}{l}\text { Characteristic PSD } \\
\text { fragments }\end{array}$ & Proposed nucleoside \\
\hline 2 & $5: 00-6: 00$ & 255.09817 & 114,123 & Unidentified nucleoside \\
\hline 8 & $12: 20-15: 00$ & $258.10966,(2.6, I C)$ & $126,138,154$ & Methylated cytidine (mC) \\
\hline 12 & 19:30-21:30 & $271.09417,(4.3, I C)$ & 139, 152, 164, 255 & PCNR \\
\hline 14 & 23:00-24:20 & $298.11331,(6.2, I C)$ & $166,281,136,150,130,147$ & 7-Methylguanosine $\left(\mathrm{m}^{7} \mathrm{G}\right)$ \\
\hline 16 & $26: 00-27: 40$ & $271.09257,(1.6, I C)$ & $139,152,164,255$ & PCNR \\
\hline 24 & $37: 30-38: 40$ & $308.08740^{\mathrm{a}},(4.5, \mathrm{IC})$ & $154,136,200,112$ & N4-Acetylcytidin $\left(\mathrm{ac}^{4} \mathrm{C}\right)$ \\
\hline 29 & $42: 00-43: 40$ & $326.14514,(4.0, I C)$ & $136,158,176,194$ & Trimethylguanosine \\
\hline 30 & $43: 00-43: 50$ & 312.12905, $(5.4, I C)$ & $138,165,180,196,296$ & $\mathrm{~N} 2$,N2-Dimethylguanosine $\left(\mathrm{m}^{2}{ }_{2} \mathrm{G}\right)$ \\
\hline 33 & $46: 20-47: 00$ & 413.13964, $(5.9, \mathrm{IC})$ & $136,214,272,282,389$ & N6-Carbamoylthreonyladenosine (t6A) \\
\hline
\end{tabular}

Numbers in bold represent nucleic base fragments

IC: internally calibrated

${ }^{\mathrm{a}}$ sodium adduct

carboxamide and 1-ribosylpyridin-2-one-5-carboxamide $^{\circ}$ were $^{\circ}$ isolated $^{\circ}$ and $^{\circ}$ identified $^{\circ}$ from $^{\circ}{ }^{\circ}$ uman $^{\circ}$ urine $^{\circ}$ in

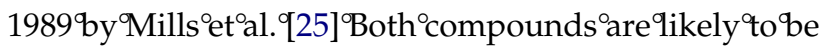
ingredients of the examined urine samples, as two HPLC fractions contain $\mathrm{m} / \mathrm{z} 271$ producing the fragment 139. The likely sources of these nucleosides are NMN or $\mathrm{NAD}^{\circ}[26]$.

Fraction 2 contained an unidentified $m / z 255$, which was analyzed with the described method as well, but only synthetically prepared structures were proposed. Further investigations for elucidation are in progress.

Other nucleosides were observed. These are a methylated cytidine $(\mathrm{m} / \mathrm{z} 258)$, an acetylated cytidine $(\mathrm{m} / \mathrm{z}$ $286)$, another methylated guanosine $(\mathrm{m} / \mathrm{z} 298)$, a double methylated guanosine $(\mathrm{m} / \mathrm{z} 312)$, a triple methylated guanosine $(\mathrm{m} / \mathrm{z} 326)$, and a nucleoside with $\mathrm{m} / \mathrm{z}$ of 413 . This nucleoside is likely N6-threonylcarbamoyladenosine (t6A).

As the two methylated guanosines, 1-methylguanosine and N2-methylguanosine, already were identified in urine with this chromatographic system, the most likely position for another methyl group is N7. N7-methylguanosine is another methylated nucleoside, which has been identified earlier in human urine.

N2,N2-dimethylguanosine and N6-carbamoylthreonyladenosine have been evaluated as tumor markers in breast $^{\circ}$ cancer $^{\circ}$ patients $^{\circ}$ in $^{\circ}$ former ${ }^{\circ}$ studies ${ }^{\circ}[27] .{ }^{\circ} \mathrm{As}^{\circ}$ described, we could also identify the masses with the corresponding fragments of these nucleosides in urine from breast cancer patients. Both nucleosides are major compounds in the urine samples, which is consistent with the previous observations.

One peak contained $\mathrm{m} / \mathrm{z} 326$, PSD produced a $\mathrm{m} / \mathrm{z}$ fragment 194, indicating the presence of a triple methylated guanosine. We assume that it is N2,N2,7-trimethylguanosine, the only known naturally occurring trimethylguanosine with three methyl groups at the base moiety. N2,N2,7-trimethylguanosine was described $^{\circ}$ to ${ }^{\circ}$ be $^{\circ}$ part $^{\circ}$ of $^{\circ} \mathrm{mRNA}^{\circ}$ and $^{\circ} \mathrm{snRNA}^{\circ}\left[4,{ }^{\circ} 28\right]^{\circ}{ }^{\circ} \mathrm{The}^{\circ}$ results of the database search for the examined fractions are $^{\circ}$ shown $^{\circ}$ in $^{\circ} \mathrm{Table}^{\circ} 4$.

\section{Conclusions}

To the authors' best knowledge this is the first time that nucleosides from urine were analyzed by MALDI-TOF and PSD-MALDI. We achieved a very high sensitivity and mass accuracy for nucleosides measured by mass spectrometric methods. It could be shown that nucleosides can be analyzed by MALDI-TOF MS using CHCA matrix with limits of detection between $100 \mathrm{fmol}$ and 10 pmol. The mass accuracy was below 10 ppm when using internal calibration.

PSD spectra of twelve nucleosides show that purines as well as pyrimidines decay under neutral loss of the sugar producing the nucleic base as a fragment. Other fragments enhance the selectivity, as they are characteristic for the different nucleosides, except those with isomeric nucleic bases, which produce similar PSD spectra.

After extraction from urine by affinity chromatography and separation via reversed-phase HPLC, several small molecular masses were observed and determined by PSD-MALDI-TOF. Some compounds could be identified as nucleosides, while others seem to be nucleosides that could not yet be identified. A number of masses did not provide any indication of being nucleosides.

With the described method including affinity chromatography, semipreparative liquid chromatography, and MALDI-TOF MS, it is possible to propose structures for nucleosides from urine. After having identified new nucleosides, they should be examined for their potential as tumor markers by quantifying and comparing both the concentrations and the entire nucleoside pattern of cancer patients and healthy subjects.

\section{Acknowledgments}

The authors thank the DFG Graduiertenkolleg Analytische Chemie of Tübingen University for the financial support of this work. They also thank Professor C. E. Müller and Dr. Burbiel, Department of Pharmaceutical Chemistry, University of Bonn, Germany, for providing synthetic nucleosides, and Professor J. H. Kim, Seoul University, South Korea, for the donation of isoguanosine. 


\section{References}

1. Schram, K. H. Urinary Nucleosides. Mass Spectrom. Rev. 1998, 17, 131-251.

2. Speer, J.; Gehrke, C. W.; Kuo, K. C.; Waalkes, T. P.; Borek, E. tRNA Breakdown Products as Markers for Cancer. Cancer 1979, 44, 2120-2123.

3. Bjoerk, G. R.; Ericson, J. U.; Gustafsson, C. E. D.; Hagervall, T. G.; Joensson, Y. H.; Wikstroem, P. M. Transfer RNA Modification. Annu. Rev. Biochem. 1987, 56, 263-287.

4. Limbach, P. A.; Crain, P. F.; McCloskey, J. A. Summary: The Modified Nucleosides of RNA. Nucleic Acids Res. 1994, 22, 2183-2196.

5. Dudley, E.; Lemiere, F.; Van Dongen, W.; Langridge, J. I.; El Sharkawi, S.; Games, D. E.; Esmans, E. L.; Newton, R. P. Analysis of Urinary Nucleosides. III. Identification of $5^{\prime}$ deoxycytidine in Urine of a Patient with Head and Neck Vancer. Rapid Commun. Mass Spectrom. 2003, 17, 1132-1136.

6. Esteva, F. J.; Hortobagyi, G. N. Prognostic Molecular Markers in Early Breast Cancer. Breast Cancer Res 2004, 6, 109-118.

7. Braun, S.; Kiechle, M.; Harbeck, N. Breast Carcinoma. Biological Principles, Classification, and Prognostic Factors. Internist 2002, 43, 329-339.

8. Borek, E.; Baliga, B. S.; Gehrke, C. W.; Kuo, C. W.; Belman, S.; Troll, W.; Waalkes, T. P. High Turnover Rate of Transfer RNA in Tumor Tissue. Cancer Res. 1977, 37, 3362-3366.

9. Marvel, C. C.; Del Rowe, J.; Bremer, E. G.; Moskal, J. R. Altered RNA Turnover in Carcinogenesis. The Diagnostic Potential of Modified Base Excretion. Mol. Chem. Neuropathol. 1994, 21, 353-368.

10. Tormey, D. C.; Waalkes, T. P.; Gehrke, C. W. Biological Markers in Breast Carcinoma-Clinical Correlations with Pseudouridine, N2,N2-Dimethylguanosine, and 1-Methylinosine. J. Surg. Oncol. 1980, 14, 267-273.

11. Itoh, K.; Konno, T.; Sasaki, T.; Ishiwata, S.; Ishida, N.; Misugaki, M. Relationship of Urinary Pseudouridine and 1-Methyladenosine to Activity of Leukemia and Lymphoma. Clin. Chim. Acta 1992, 206, 181-189

12. Nakano, K.; Shindo, K.; Yasaka, T.; Yamamoto, H. ReversedPhase High-Performance Liquid Chromatographic Investigation of Mucosal Nucleosides and Bases and Urinary Modified Nucleosides of Gastrointestinal Cancer Patients. J. Chromatogr. 1985, 343, 21-33.

13. Waalkes, T. P.; Abeloff, M. D.; Ettinger, D. S.; Woo, K. B.; Gehrke, C. W.; Kuo, K. C.; Borek, E. Modified Ribonucleosides as Biological Markers for Patients with Small Cell Carcinoma of the Lung. Eur. J. Cancer Clin. Oncol. 1982, 18, 1267-1274.

14. Uziel, M.; Smith, L. H.; Taylor, S. A. Modified Nucleosides in Urine: Selective Removal and Analysis. Clin. Chem. 1976, 22, 1451-1455.

15. Gehrke, C. W.; Kuo, K. C. Ribonucleoside Analysis by Reversed-Phase High-Performance Liquid Chromatography. J. Chromatogr. A 1989, 471, 3-36.
16. Liebich, H. M.; Di Stefano, C.; Wixforth, A.; Schmid, H. R. Quantitation of Urinary Nucleosides by High-Performance Liquid Chromatography. J. Chromatogr. A 1997, 763, 193197.

17. Cohen, L. H.; Gusev, A. I. Small Molecule Analysis by MALDI Mass Spectrometry. Anal. Bioanal. Chem. 2002, 373, 571-586.

18. Lidgard, R.; Duncan, M. W. Utility of Matrix-Assisted Laser Desorption/Ionization Time-of-Flight Mass Spectrometry for the Analysis of Low Molecular Weight Compounds. Rapid Commun. Mass Spectrom. 1995, 9, 128-132.

19. Koomen, J. M.; Russell, D. H. Ultraviolet/Matrix-Assisted Laser Desorption/Ionization Mass Spectrometric Characterization of 2,5-Dihydroxybenzoic Acid-Induced Reductive Hydrogenation of Oligonucleotides on Cytosine Residues. J. Mass Spectrom. 2000, 35, 1025-1034.

20. Dudley, E.; El Sharkawi, S.; Games, D. E.; Newton, R. P. Analysis of Urinary Nucleosides. I. Optimization of High Performance Liquid Chromatography/Electrospray Mass Spectrometry. Rapid Commun. Mass Spectrom. 2000, 14, 12001207.

21. Crow, F. W.; Tomer, K. B.; Gross, M. L.; McCloskey, J. A.; Bergstrom, D. E. Fast Atom Bombardment Combined with Tandem Mass Spectrometry for the Determination of Nucleosides. Anal. Biochem. 1984, 139, 243-262.

22. Wilson, M. S.; McCloskey, J. A. Chemical Ionization Mass Spectrometry of Nucleosides. Mechanisms of Ion Formation and Estimations of Proton Affinity. J. Am. Chem. Soc. 1975, 97, 3436-3444.

23. Xu, G.; Di Stefano, C.; Liebich, H. M.; Zhang, Y.; Lu, P. Reversed-Phase High-Performance Liquid Chromatographic Investigation of Urinary Normal and Modified Nucleosides of Cancer Patients. J. Chromatogr. B Biomed. Sci. Appl. 1999, 732, 307-313.

24. Dutta, S. P.; Crain, P. F.; McCloskey, J. A.; Chheda, G. B. Isolation and Characterization of 1-b-D-Ribofuranosylpyridin4-One-3-Carboxamide from Human Urine. Life Sci. 1979, 24, 1381-1388.

25. Mills, G. C.; Davis, N. J.; Lertratanangkoon, K. Isolation and Identification of 1-Ribosylpyridone Nucleosides from Human Urine. Nucleosides Nucleotides 1989, 8, 415-430.

26. Chang, M. L.; Johnson, B. C. N-Methyl-4-Pyridone-5-Carboxamide as a Metabolite of Nicotinic Acid in Man and Monkey. J. Biol. Chem. 1961, 236, 2096-2098.

27. Schlimme, E.; Boos, K. S.; Schwarzenau, E.; Frister, H.; Ott, F. G.; Raezke, K. P.; Wilmers, B. Dual Column HPLC Analysis of Modified Ribonucleosides as Urinary Pathobiochemical Markers in Clinical Research. Nucleosides Nucleotides 1990, 9, 407-410.

28. Saponara, A. G.; Enger, M. D. Occurrence of N2,N2,7-Trimethylguanosine in Minor RNA Species of a Mammalian Cell Line. Nature 1969, 223, 1365-1366. 